\title{
RELATIONSHIP OF EXPLOSIVE MUSCLE MUSCLE TOWARDS DRIBBLING SKILLS IN FUTSAL GAME IN DEHASEN ACADEMY
}

\section{HUBUNGAN DAYA LEDAK OTOT TUNGKAI TERHADAP KETERAMPILAN DRIBBLING PADA PERMAINAN FUTSAL DI AKADEMI DEHASEN}

\author{
Yogi Angga Putra ${ }^{\perp}$, Arifto Juniardi ${ }^{2}$ \\ ${ }^{1}$ Study Program Phsycal Education Study Program, Universitas Dehasen Bengkulu, \\ Indonesia \\ 2,Departemen Phsycal Education Study Program, Universitas Dehasen Bengkulu, \\ Indonesia
}

Corresponding Author: : Yogiangga@gmail.com

\section{How to Cite :}

Putra.Y.A., Juniardi. A. (2020). Relationship of Explosive Muscle Muscle Towards Dribbling Skills In Futsal Game In Dehasen Academy. Hanoman Journal, 1(1).

\section{ARTICLE HISTORY}

Received [ $x x$ Month $x x x x$ ] Revised [ $x x$ Month $x x x x$ ] Accepted [ $x x$ Month $x x x x]$

Kata Kunci :

Daya Ledak Otot Tungkai, Keterampilan Dribbling

Keywords :

Leg Muscle Explosive Power Dribbling Skills
This is an open access article under the $C C-B Y-S A$ license

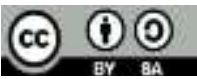

\section{ABSTRAK}

Berdasarkan pengamatan peneliti terhadap pelaksanaan Kegiatan di klub Akademi Dehasen, bahwa keterampilan Dribbling para atlet kurang baik sehingga menyebabkan bola sering lepas kendali. Masalah inilah diduga disebabkan oleh beberapa faktor, antara lain rendahnya tingkat daya ledak otot tungkai dari atlet. Penelitian ini bertujuan untuk mengetahui Hubungan daya ledak otot tungkai terhadap Keterampilan Dribbling. Metode penelitian ini adalah metode korelasional. Populasi penelitian ini seluruh pemain klub Futsal Akademi Dehasen sebanyak 25 orang putera sedangkan sampel diambil secara total sampling, Tempat pelaksanaan penelitian di lapangan futsal Unived, adapun waktu penelitian adalah bulan April 2019. Data Daya Ledak otot Tungkai diambil dengan tes vertical jump, dan data Kemampuan Dribbling diambil dengan tes Dribbling. Teknik analisis data penelitian ini menggunakan teknik dengan analisis korelasi.Hasil analisis data menunjukkan bahwa: Terdapat hubungan yang signifikan antara Daya Ledak otot Tungkai (X) terhadap keterampilan dribbling pada atlet futsal di Akdemi Universitas Dehasen Bengkulu, dengan nilai $r_{x y}=0,93>r_{(0,05)(19)}=0,396$.

\begin{abstract}
Based on the observations on the implementation of activities at the Academy of Dehasen club, the dribbling skills of the athletes were not good enough to cause the ball to go out of control. This problem is allegedly due to several factors, including the low levels of leg muscle explosive power of the athletes. This study aims to determine the correlation between leg muscle explosion power on dribbling skills. This research method is a correlational method. The population of this study were 25 Dehasen Futsal Club players, while the samples were taken in total sampling. This research was conducted at Unived futsal field in April 2019. Explosive power of leg muscles data were taken by vertical jump test, and the data of dribbling were taken through dribbling test. The data analysis technique used was a technique of correlation analysis. The results of the data analysis show that: There is a significant correlation between leg muscle explosive power $(X)$ on dribbling skills in futsal athletes in the Academy of Dehasen University of Bengkulu, with $r x y=0.93>r(0.05)(19)=0.396$.
\end{abstract}

\section{PENDAHULUAN}

Pendidikan jasmani dan olahraga merupakan proses pendidikan melalui aktivitas jasmani dan olahraga yang terpilih untuk mencapai tujuan pendidikan. Tujuannya adalah agar membantu anak untuk tumbuh dan berkembang secara wajar 
sesuai dengan tujuan pendidikan nasional. Pendidikan jasmani dan olahraga merupakan bagian yang tak terpisahkan dari pendidikan umum. Pendidikan jasmani dan olahraga pada hakikatnya adalah proses pendidikan yang memanfaatkan aktifitas fisik. Olahraga merupakan suatu bidang ilmu yang mempunyai kedudukan yang sangat penting dalam dunia pendidikan.

Pendidikan jasmani olahraga dan kesehatan merupakan bagian integral dari sistem pendidikan secara keseluruhan. Pendidikan jasmani diajarkan di sekolah mempunyai peranan penting untuk memberikan kesempatan kepada peserta didik untuk terlibat langsung dalam berbagai pengalaman belajar melalui aktivitas jasmani, olahraga dan kesehatan yang terpilih yang dilakukan secara sistematis.

Pendidikan sebagai suatu proses pembinaan manusia yang berlangsung seumur hidup, hal ini pula yang menjadikan pendidikan olahraga berperan dalam membangun karakter suatu bangsa. Olahraga merupakan sarana, bukan hanya di Indonesia di negara-negara lainpun setiap orang meluangkan waktu untuk melakukan melakukan aktivitas jasmani, ini terbukti bahwa olahraga juga sudah menjadi gaya hidup untuk menuju kehidupan yang sehat. Olahraga sudah menjadi sebuah gaya hidup bagi sebagian orang, bahkan untuk sebagian orang yang lain olahraga menjadi sebuah kebutuhan mendasar dalam hidup.

Olahraga sendiri merupakan serangkaian gerak yang teratur dan terencana untuk memelihara dan meningkatkan kemampuan gerak yang bertujuan untuk mempertahankan hidupserta meningkatkan kualitas hidup seseorang. Olahraga menjadi sangat penting karena tidak terlepas dari kebutuhan mendasar manusia itu sendiri yang pada prinsipnya selalu bergerak. Tujuan seseorang berolahraga adalah untuk meningkatkan kesehatan yang menyeluruh baik jasmani maupun rohani. Olahraga mempunyai fungsi dan manfaat sesuai dengan kebutuhan, selain olahraga sebagai sarana rekreasi, olahraga juga dapat pula sebagai prestasi.

Olahraga futsal sendiri adalah olahraga yang sangat digemari dari semua lapisan masyarakat, bahkan olahraga futsal ini adalah olahraga yang sangat populer di dunia. Dalam batasan pendidikan jasmani, harus pula dipertimbangkan kaitannya dengan permainan, olahraga serta prestasi. Permainan menjadi aktivitas bermain, terutama merupakan aktivitas kegembiraan. Pembekalan pengalaman belajar pendidikan jasmani diarahkan untuk membina pertumbuhan kondisi fisik dan pengembangan mental yang lebih baik, sekaligus membentuk pola hidup yang sehat.

Olahraga futsal merupakan olahraga yang dimainkan oleh lima orang termasuk penjaga gawang dan biasanya dimainkan di dalam suatu ruangan. Seperti halnya dengan olahraga sepakbola, futsal juga olahraga yang memiliki minat yang banyak oleh kalangan masyarakat, dikarenakan olahraga ini dapat dimainkan disemua lapisan masyarakat baik kalangan atas maupun kalangan bawah. Futsal merupakan cabang olahraga yang popular dan digemari oleh seluruh lapisan masyarakat terutama kaum laki-laki mulai dari anak-anak, remaja dan dewasa.

Olahraga futsal sendiri memiliki beberapa teknik dasar diantaranya adalah, passing, shooting, dribbling dan kontrol. Dribbling merupakan teknik dasar sangat mempengaruhi permainan. Hal ini disebabkan dribbling harus dimiliki setiap pemain. Olahraga futsal ini dibutuhkan akselerasi dribbling yang cepat karena bukan otot saja yang digunakan, namun keterampilan dasarpun harus dimiliki oleh setiap pemain.

Dari beberapa penjelasan mengenai teknik dasar yang ada di atas, teknik dribbling merupakan salah satu teknik yang harus dikuasi oleh setiap pemain futsal. Dribbling merupakan salah satu teknik yang selalu digunakan pemain untuk mengecoh lawan. Setiap pemain yang melakukan dribbling harus selalu ditingkatkan guna menghasilkan pola permainan yang baik serta yang paling utama adalah untuk memenangi pertandingan. 
Selain keterampilan dribbling, dalam aktivitas olahraga dapat disebutkan juga otot sebagai motor pengerak dalam setiap aktivitas yang dilakukan guna mendapatkan hasil yang ingin dicapai dan proses pencapaian prestasi semaksimal mungkin. Maka dari itu pemain futsal sangat membutuhkan daya ledak otot tungkai yang baik dalam melakukan dribbling. Daya ledak otot dalam melakukan melakukan dribbling memiliki faktor penting pada saat bermain futsal. Untuk mendapatkan kualitas dribbling yang baik sangat membutuhkan latihan fisik yang terprogram dan dengan bimbingan pelatih untuk mengarahkan bagiamana dapat menghasilkan daya ledak otot tungkai dalam melakukan dribbling yang terarah dengan teknik yang benar.

\section{LANDASAN TEORI Permainan Futsal}

Futsal merupakan suatu aktifitas olahraga atau permainan yang dimainkan di dalam ataupun di luar ruangan. Olahraga futsal ini juga memiliki keunggulan, yaitu lapangan tidak luas, dimainkan oleh lima pemain termasuk kiper dan memakai bola ringan, serta memiliki minat yang banyak oleh kalangan masyarakat, dikarenakan olahraga ini dapat dimainkan dari semua lapisan masyarakat baik pelajar ataupun mahasiswa, dari kalangan atas maupun kalangan bawah, baik anak kecil sampai tingkat yang lebih dewasa.

Futsal dimainkan dengan dua babak masing-masing babak dengan waktu 10 sampai 20 menit tergantung dengan tingkat usia yang diperlombakan. Menurut Mulyono (2017:5) "Futsal merupakan salah satu cabang olahraga yang termasuk dalam permainan bola besar". Pada tahun 2002 olahraga ini mulai masuk ke Indonesia dengan cepat dan mendapatkan tempat ruang di hati para pecinta olahraga khususnya sepak bola.

\section{Daya Ledak Otot Tungkai}

Daya ledak menurut Peter (2010:136) adalah hasil kekuatan yang diterapkan oleh suatu otot yang cepat dengan kontraksi yang kuat menjadi lebih powerfull (tenaga penuh) dibandingkan dengan kekuatan otot yang menerapakan pelan-pelan. Perbedaan karakter otot terletak pada kemampuannya berkontraksi. Aksi otot ini biasanya dikenal sebagai kontraksi otot. Otot merupakan alat penggerak aktif karena mampu berkontraksi dan berfungsi menggerakkan organ-organ tertentu dalam tubuh. Menurut Rika (2015:42-43), “Otot memiliki tiga kemampuan khusus, yaitu:

1. Kontraktibilitas: Kemampuan untuk berkontrkasi/memendek

2. Ekstensibilitas: Kemampuan untuk melakukan gerakan kebalikan dari gerakan yang ditimbulkan saat kontraksi

3. Elastisitas: Kemampuan otot untuk kembali pada ukuran semula setelah berkontraksi. Saat kembali pada ukuran semula otot disebut dalam keadaan relaksasi.

Dari perspektif yang lain daya ledak adalah tingkat waktu selama pekerjaan fisik yang sedang dilakukan. Kemampuan dari seorang atlit untuk meningkatkan jarak dari suatau obyek atau bagian badan ketika penggunaan suatu kekuatan akan dipengaruhi pencapaian beberapa keterampilan (Peter, 2010:136). Daya ledak/power otot adalah komponen yang sangat penting untuk meningkatkan kondisi fisik secara keseluruhan.

\section{METODE PENELITIAN}

Penelitian ini akan dilaksanakan di Lapangan Futsal Dehasen bertempat di Jalan. Meranti Raya N0.32, Sawah Lebar, Ratu Agung, Kota Bengkulu. Waktu 
penelitian akan dilaksanakan di lapangan Futsal Dehasen pada waktu latihan yaitu pada hari Rabu dan Jumat pada pukul 16:00

Metode penelitian penelitian menurut Subagyo (2015:2) merupakan suatu cara atau jalan untuk memperoleh kembali pemecahan terhadap segala permasalahan. Metode penelitian yang digunakan dalam penelitian ini adalah dengan menggunakan metode korelasional (correlational research).

Sugiyono, (2009:115) menjelaskan “Populasi adalah wilayah generalisasi yang terdiri atas obyek atau subyek yang mempengaruhi kuantitas dan karakteristik tertentu yang ditetapkan oleh peneliti untuk dipelajari dan kemudian ditarik kesimpulannya:". Populasi dalam penelitian ini yaitu seluruh pemain futsal di Akademi Dehasen Kota Bengkulu yang berjumlah 25 orang.

Menurut Sugiyono (2009:116) sampel adalah sebagian dari jumlah dan karakteristik yang dimiliki populasi tersebut. Sampel yang digunakan dalam penelitian ini adalah dengan menggunakan total sampling. Dimana seluruh populasi dijadikan sampel yaitu berjumlah 25 orang.

\section{HASIL \\ Deskripsi Data}

Sesuai dengan rancangan penelitian dan studi kepustakaan yang telah dikemukan terdahulu, analisis data dilakukan terhadap hasil tes kedua variabel. Kedua variabel tersebut adalah daya ledak otot tungkai sebagai variabel bebas dan keterampilan dribbling pada atlet futsal Akademi Dehasen sebagai variabel terikatnya. Selanjutnya akan dijabarkan hasil dari penelitian sebagai berikut:

1. Hasil Tes Daya Ledak Otot Tungkai (X)

Dari hasil pengukuran Daya Ledak Otot Tungkai yang dilakukan terhadap atlet Futsal Universitas Dehasen Bengkulu didapat skor tertinggi 67.94 dan skor terendah 31.00 berdasarkan data tersebut rata-rata hitung (mean) 48.58. Menurut Fardi Adnan (2013:19) bahwa Langkah awal, tentukan banyak kelas dengan rumus $1+3.3 \log 25$ (sampel) = 5.61, dapat dibulatkan menjadi 6 , dan mencari panjang kelas dengan rumus nilai tertinggi dikurang nilai terendah di bagi banyak kelas adalah 67.94-31.00 $=36.94 / 6=6.58$. Distribusi kategori daya ledak otot tungkai yang dilakukan terhadap atlet futsal Akademi Universitas Dehasen Bengkulu dapat dilihat pada tabel berikut :

Tabel 1. Distribusi Frekuensi Data Daya Ledak Otot Tungkai

\begin{tabular}{|c|c|c|c|}
\hline No & \multicolumn{1}{|c|}{ Kelas Interval } & Frekuensi Absolut & $\begin{array}{c}\text { Frekuensi Relatif } \\
\text { (\%) }\end{array}$ \\
\hline 1. & $31.00 \mathrm{~cm}-37.58 \mathrm{~cm}$ & 3 Orang & $12 \%$ \\
\hline 2. & $37.59 \mathrm{~cm}-44.17 \mathrm{~cm}$ & 5 Orang & $20 \%$ \\
\hline 3. & $44.18 \mathrm{~cm}-50.76 \mathrm{~cm}$ & 5 Orang & $20 \%$ \\
\hline 4. & $50.77 \mathrm{~cm}-57.35 \mathrm{~cm}$ & 5 Orang & $20 \%$ \\
\hline 5. & $57.36 \mathrm{~cm}-61.94 \mathrm{~cm}$ & 2 Orang & $8 \%$ \\
\hline 6. & $61.95 \mathrm{~cm}-68.53 \mathrm{~cm}$ & 5 Orang & $20 \%$ \\
\hline
\end{tabular}

Dari tabel 1. di atas dapat disimpulkan bahwa dari 25 atlet futsal Akademi Dehasen. Sebanyak 3 orang atlet (12\%) memiliki kategori nilai $31.00 \mathrm{~cm}-37.58$ $\mathrm{cm}$. sebanyak 5 orang atlet $20 \%$ memiliki kategori nilai $37.59 \mathrm{~cm}-44.17 \mathrm{~cm}$. Sebanyak 5 atlet $20 \%$ memiliki kategori nilai $44.18 \mathrm{~cm}-50.76 \mathrm{~cm}$. Sebanyak 5 orang atlet $20 \%$ memiliki kategori nilai $50.77 \mathrm{~cm}-57.35 \mathrm{~cm}$. Sebanyak 2 orang atlet $8 \%$ memiliki kategori nilai $55.36 \mathrm{~cm}-61.94 \mathrm{~cm}$. Dan sebanyak 5 orang atlet $20 \%$ memiliki kategori nilai $61.95 \mathrm{~cm}-68.53 \mathrm{~cm}$ dapar dilihat diagram batang di bawah ini 
Gambar 1. Diagram Batang Hasil Tes Daya Ledak Otot Tungkai

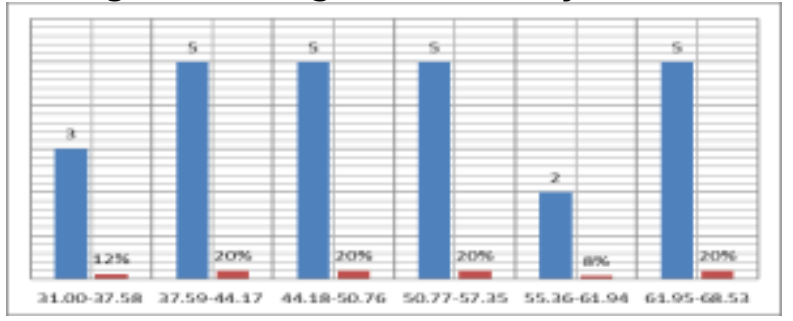

2. Hasil Tes Keterampilan Dribbling (Y)

Dari hasil pengukuran dribbling yang dilakukan terhadap atlet Futsal Akademi Universitas Dehasen Bengkulu terdapat skor tertinggi 64.61dan skor terendah 20.61, berdasarkan data tersebut rata-rata hitung (mean) 47.9. Langkah awal, tentukan banyak kelas dengan rumus, Menurut Fardi Adnan (2013:19) bahwa 1+3.3 log 25 (sampel) $=5.5$, dapat menjadi 5 , dan mencari panjang kelas dengan rumus nilai tertinggi dikurang nilai terendah di bagi banyak kelas adalah $(64.61-20.61) / 5 .=8.8$. Distribusi kategori keterampilan dribbling yang dilakukan atlet Akademi Dehasen Bengkulu dapat dilihat pada tabel berikut :

Tabel 2. Distribusi Frekuensi Hasil Tes Keterampilan dribbling (Y).

\begin{tabular}{|l|c|c|c|}
\hline No & Kelas Interval & Frekuensi Absolut & Frekuensi Relatif (\%) \\
\hline 1. & 20.61 detik -29.41 detik & 1 & $4 \%$ \\
\hline 2. & 29.42 detik -38.22 detik & 1 & $4 \%$ \\
\hline 3. & 38.23 detik -47.03 detik & 6 & $24 \%$ \\
\hline 4. & 47.04 detik -55.84 detik & 11 & $44 \%$ \\
\hline 5. & 55.85 detik -64.64 detik & 6 & $24 \%$ \\
\hline
\end{tabular}

Dari tabel di atas dapat disimpulkan bahwa dari 25 atlet futsal Akademi Dehasen. Sebanyak 1 orang atlet (4\%) memiliki kategori nilai 20.61-29.41. sebanyak 1 orang atlet $4 \%$ memiliki kategori nilai 29.42-38.22. Sebanyak 6 atlet $24 \%$ memiliki kategori nilai 38.23-47.03. Sebanyak 11 orang atlet $44 \%$ memiliki kategori nilai 47.04-55.84 . Sebanyak 6 orang atlet 24\% memiliki kategori nilai 55.85-64.64 .

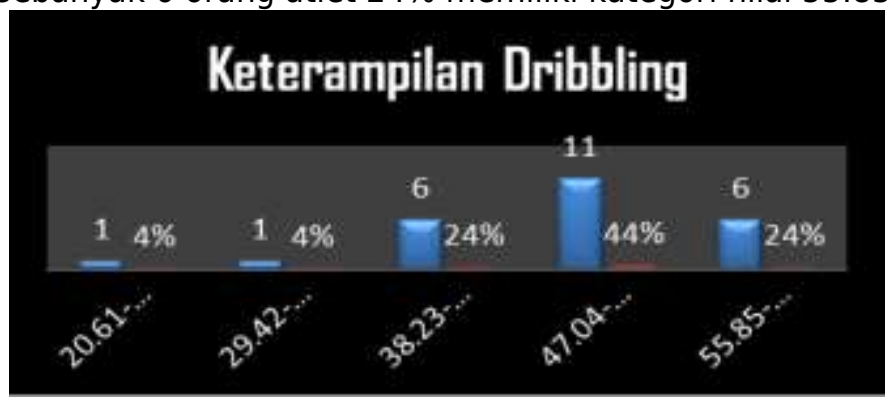

Gambar 2. Diagram Batang Hasil Tes Dribbling

3. Uji normalitas data

Sebelum melakukan pengujian hipotesis yang diajukan dalam penelitian ini, maka terlebih dahulu dilakukan uji prasyarat analisis data yaitu uji normalitas data. Dalam uji normalitas data ini peneliti menggunakan uji normalitas data lilliefors. Adapun hasil analisis dapat dilihat pada tabel di bawah ini :

Tabel 3. Uji Normalitas Data Variabel X dan Y

\begin{tabular}{|c|l|c|c|c|}
\hline No & \multicolumn{1}{|c|}{ Variabel } & $\mathbf{L}_{\text {hitung }}$ & $\mathbf{L}$ tabel & Keterangan \\
\hline 1. & Daya Ledak otot tungkai & $\mathbf{0 . 0 6 6}$ & $\mathbf{0 , 1 7 3}$ & Normal \\
\hline 2. & Keterampilan Dribbling & $\mathbf{0 . 1 1 0 4 9}$ & $\mathbf{0 , 1 7 3}$ & Normal \\
\hline
\end{tabular}

28 | Yogi Angga Putra, Arifto Juniardi; Relationship of Explosive Muscle Muscle... 
Dari tabel di atas menunjukan bahwa hasil pengujian untuk kecepatan lari (X) skor $L_{\text {hitung }} \mathbf{0 . 0 6 6}$ dengan $n=25$ sedangkan $L_{\text {tabel }}$ pada taraf signifikan $5 \%$ atau 0,05 diperoleh 0,173 . Karena $L_{\text {hitung }}$ lebih kecil dari $L_{\text {tabel }}$ sehingga dapat disimpulkan bahwa skor yang diperoleh dari vertical jump berdistribusi normal. Selain itu tabel tersebut di atas juga menunjukan bahwa hasil pengujian untuk keterampilan dribbling $(Y)$ skor $L_{\text {hitung }}=\mathbf{0 . 1 1 0 4 9}$ dengan $n=25$, sedangkan $L_{\text {tabel }}$ pada taraf signifikan $5 \%$ atau 0,05 diperoleh 0,173 . Karena $L_{\text {hitung }}$ lebih kecil dari pada $L_{\text {tabel }}$ sehingga dapat disimpulkan bahwa skor yang diperoleh dari keterampilan dribbling berdistribusi normal.

4. Uji Homogenitas Data

Uji prasyarat analisis data setelah melakukan uji normalitas data maka dilakuakan uji homogenitas data dengan menggunakan uji varians (uji F dari Hevley) dapat di lihat pada tabel berikut ini :

Tabel 4. Uji Homogenitas Data Variabel X dan $Y$

\begin{tabular}{|c|l|l|l|l|l|}
\hline No & \multicolumn{1}{|c|}{ Variabel } & \multicolumn{1}{c}{ Varians } & \multicolumn{1}{c}{$\mathbf{F}_{\text {hitung }}$} & \multicolumn{1}{c}{$\mathbf{F}_{\text {tabel }}$} & Ket \\
\hline 1 & Daya Ledak Otot Tungkai & 10.01 & 1.001 & 3,40 & Homogen \\
\hline 2 & Keterampilan Dribbling & 10.03 & & & \\
\hline
\end{tabular}

Dari tabel di atas menunjukan bahwa hasil pengujian varians untuk Daya ledak Otot Tungkai $(\mathrm{X})$ didapat skor 10.01, sedangkan hasil pengujian varians untuk keterampilan dribbling $(\mathrm{Y})$ didapat skor 10.03 sehinggga didapat $\mathrm{F}_{\text {hitung }}$ dengan menggunakan uji $\mathrm{F}$ dari Hevley diperoleh skor 1,.01. Sedangkan untuk nilai $F_{\text {tabel }}$ dengan tarap signifikan $5 \%$ atau 0,05 adalah $=3,40$ karena $F_{\text {hitung }}(1.01)$ lebih kecil dari $F_{\text {tabel }}(3,40)$ maka data dapat disimpulkan bahwa skor yang diperoleh untuk daya ledak otot tungkai $(\mathrm{X})$ terhadap keterampilan dribling $(\mathrm{Y})$ memiliki data yang homogen.

5. Hasil Uji Hipotesis

Analisis data penelitian yang digunakan untuk menguji hipotesis terdiri atas analisis korelasi sederhana. Hipotesis dalam penelitian ini adalah "Ada hubungan yang signifikan antara daya ledak otot tungkai terhadap keterampilan dribbling pada atlet Futsal Akademi Dehasen Bengkulu". Hasil uji hipotesis dengan menggunakan analisis koefisien korelasi product moment dapat dilihat pada tabel 5. berikut ini :

Tabel 5. Koefisien Korelasi Variabel (X) Terhadap Variabel (Y).

\begin{tabular}{|c|c|c|c|}
\hline Korelasi & $\mathbf{r}_{\text {hitung }}$ & $\boldsymbol{r}_{\text {tabel }}$ & Keterangan \\
\hline$r_{\mathrm{xy}}$ & 0,93 & 0,396 & Signifikan \\
\hline
\end{tabular}

Berdasarkan hasil analisis tersebut di atas diperoleh koefisien korelasi daya ledak otot tungkai terhadap keterampilan dribbling atlet futsal Akademi sebesar 0,95 bernilai positif, artinya semakin besar skor yang diperoleh maka semakin kuat hubungan antara kedua variabel. Uji keberartian koefisien korelasi tersebut dilakukan dengan cara harga $r_{\text {hitung }}$ dengan $r_{\text {tabel }}$ pada $\alpha=5 \%$ dengan $\mathrm{N}=25$ diperoleh $r_{\text {tabel }}$ sebesar 0,396 Karena koefisien korelasi antara $r_{x . y}=0,93>r_{(0,5)(25)}$ $=0,396$ berarti hubungan daya ledak otot tungkai terhadap keterampilan dribbling atlet futsal Akademi Dehasen Bengkulu adalah signifikan. Dengan demikian hipotesis yang berbunyi "ada hubungan yang kuat antara daya ledak otot tungkai terhadap keterampilan dribbling atlet futsal Akademi Dehasen Bengkulu", diterima. Artinya ada hubungan daya ledak otot tungkai terhadap keterampilan dribbling atlet futsal Akademi Dehasen Bengkulu.

\section{Pembahasan}


Menurut Mulyono (2014: 54) "dribbling atau menggiring bola yaitu untuk menguasai bola dan menciptakan peluang mencetak gol". Teknik ini harus dikuasi oleh setiap pemain futsal agar mempu menguasai bola dengan baik saat bola berada di kakinya. Pemain futsal yang memiliki kemampuan menggiring bola yang baik akan berusaha melewati lawan apabila bola tidak dapat di passing ke teman karena ketatnya pertahanan.

Menggiring bola adalah menendang bola terputus-putus atau pelan-pelan". Menggiring bola bertujuan untuk mendekatkan bola ke pertahanan lawan, melewati lawan, dan menghambat permainan. Kaki yang digunakan untuk menggiring bola sama dengan kaki yang digunakan untuk menendang bola. Dribbling merupakan kemampuan yang dimiliki setiap pemain dalam menguasai bola sebelum diberikan kepada temannya untuk menciptakan peluang dalam mencetak gol. Menggiring bola dilakukan dengan menggunakan sisi bawah sepatu, kaki bagian dalam dan dengan menggunakan kaki bagian luar, serta punggung kaki. Untuk mengahasilkan dribbling yang maksimal maka di butuhkan suatu kondisi fisik seperti komponen daya ledak otot tungkai. Daya ledak otot tungkai menurut Peter (2010:136) adalah hasil kekuatan yang diterapkan oleh suatu otot yang cepat dengan kontraksi yang kuat menjadi lebih powerfull (tenaga penuh).Berdasarkan hasil penelitian menunjukan bahwa ada hubungan yang signifikan antara daya ledak otot tungkai terhadap keterampilan dribbling atlet futsal Akademi Dehasen Bengkulu, dengan nilai $r_{x . y}=$ $0,93>r_{(0,05)(19)}=0,396$. Dari hasil penelitian ini Dribbling merupakan salah satu teknik yang selalu digunakan pemain untuk mengecoh lawan sehingga membongkar pertahanan lawan. Selain keterampilan dribbling, daya ledak otot tungkai dalam futsal dapat disebutkan sebagai poin yang penting dalama melakukan dribbling yang cepat dalam setiap aktivitas dribbling speed

Dribbling yang bagus membutuhkan latihan daya ledak otot tungkai yang terprogram dan dengan bimbingan pelatih untuk mengarahkan bagiamana dapat menghasilkan dribbling yang terarah dengan teknik yang benar dan cepat. Dari penjelasan di atas dapat disimpulkan bahwa salah satu tahapan yang harus dilakukan didalam melakukan dribbling harus memiliki daya ledak otot tungkai yang bagus. Pernyataan inilah yang menjadikan dasar bahwa daya ledak otot tungkai sangat dibutuhkan dalam melakukan dribbling dalam permainan futsal. Dengan daya ledak otot tungkai yang besar maka persentase keberhasilan dalam melakukan dribbling akan semakin tinggi.

\section{KESIMPULAN}

Berdasarkan hasil penelitian dan pembahasan, maka didapat kesimpulan sebagai berikut : Terdapat hubungan yang signifikan antara daya ledak otot tungkai (X) terhadap keterampilan dribbling pada atlet futsal di Akdemi Universitas Dehasen Bengkulu, dengan nilai $r_{x y}=0,93>r_{(0,05)(19)}=0,396$.

\section{SARAN}

1. Bagi pelatih futsal agar dapat memberikan program latihan daya ledak otot tungkai untuk melatih keterampilan dribbling futsal sehingga dapat mendukung peningkatan kualitas hasil latihan.

2. Bagi atlet agar dapat mengembangkan keterampilan dribbling dalam permainan futsal dengan menggunakan latihan daya ledak otot tungkai.

3. Bagi peneliti yang ingin melanjutkan penelitian ini agar dapat menemukan variabel lain yang dapat memberikan sumbangsih terhadap keterampilan dribbling dalam permainan futsal selain kecepatan. 


\section{DAFTAR PUSTAKA}

1. Amung, Ma'mun dkk. 2000.Perkembangan Gerak dan Belajar Gerak. Jakarta: Depdiknas

2. Arfianto, Dwi. 2010. Survei Keterampilan Teknik Dasar Bermain Bola Voli Siswa Putra Peserta Ekstrakulikuler Bola Voli di SMA/SMK/MA Sekecamatan Sukarejo Kabupaten Kendal Tahun 2010/2011.Skripsi.FIK UNS

3. Arikunto, Suharsimi. 2006.Prosedur Penelitian Suatu Pendekatan Taktik. Jakarta: Rineka Cipta

4. Arsil. 2009. Evaluasi Pendidikan Jasmani Dan Olahraga. Padang: Wineka Media.

5. Bachtiar. 2007. Permainan Besar II Bola Voli dan Bola Tangan. Jakarta Universitas Terbuka.

6. Bompa, Tudor. 1983. Theory and Methodology Of Training, Kendall Hunt Publishing Company, IOWA.

7. Erianti. 2004. Buku Ajar Bola Voli. Padang: SUKABINA Press.

8. Hidayat, Hermy Susiana. 2013. Tingkat Keterampilan Servis Atas Passing Bawah dan Passing Atas Siswa Putra Peserta Ekstrakulikuler Bola Voli di SMKN Pandak Bantul. Skripsi. FIK UNY

9. Kardiyanto, Whinata dkk. 2015. Bola Voli. Jawa Tengah: UNS Press.

10. Kurniawan, febi dkk. 2015. Ilmu Kepelatihan Dasar. Bandung: Alfabeta.

11. Muhajir. 2003. Pendidikan Jasmani . Jakarta: Yudistira

12. Nuril, Ahmadi. 2007. Panduan Olahraga Bola Voli. Surakarta: Era Pustaka Utama

13. Ridwan. 2015.Dasar-Dasar Statistika. Bandung: CV. ALFABETA

14. Sugiyono.2012.Metode Penelitian Pendidikan. Bandung:CV. ALFABETA

15. Sukadiyanto. 2005. Pengantar Teori dan Metodologi Melatih Fisik. Yogyakarta: FIK UNY.

16. Juliantine, Tite dkk. 2007. Modul Mata Kulia Teori Latihan. Bandung: FPOK UPI.

17. UU No. 3/2005. Sistem Keolahragaan Nasional. Jakarta: KEMENPORA

18. Widiastuti. 2015.Tes Dan Pengukuran Olahraga. Jakarta: RAJAWALI PERS 